\title{
Probabilistic characteristics of lag time between meteorological and hydrological droughts using a Bayesian model
}

\author{
Muhammad Nouman Sattar ${ }^{1}$ and Tae-Woong Kim ${ }^{2, *}$ \\ ${ }^{I}$ Department of Civil and Environmental Engineering, Hanyang University, Seoul, Republic of Korea \\ ${ }^{2}$ Department of Civil and Environmental Engineering, Hanyang University, Ansan, Republic of Korea
}

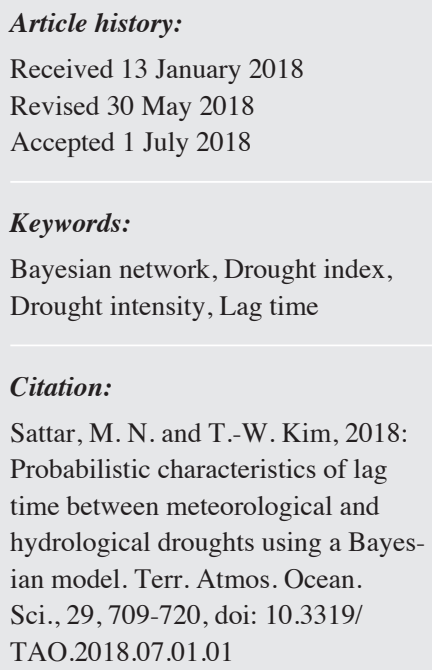

\begin{abstract}
The reliable estimation of lag time and its association with meteorological drought is very important for early mitigation of hydrological drought. The relationship between meteorological and hydrological droughts is very complex because it depends on watershed characteristics as well as climatic factors. The objective of this study is to figure out probabilistic relationships of weekly lag time between the hydrological drought defined by Standardized Runoff Index (SRI) and the meteorological drought defined by Standardized Precipitation Index (SPI) and Standardized Evapotranspiration Index (SPEI) using a Bayesian network model. The results showed that the lag time varied spatially with the intensity of meteorological droughts. The results also revealed the probabilistic relationships that meteorological droughts with moderate intensity resulted in a higher probability of longer lag time, whereas meteorological droughts with severe intensity led to a lower probability of longer lag time. The probability of lag time also varied with meteorological drought indices; at the same intensity, the probability of lag time occurring is higher in the case of SPI and lower in the case of SPEI. These results will be very helpful for early mitigating hydrological drought hazard and making strategies to cope with losses from hydrological droughts.
\end{abstract}

\section{INTRODUCTION}

Incredible variations have been perceived in the world climate and environment such as global warming, which has resulted in the occurrence of numerous drought events (Kunkel 2003; Beniston and Stephenson 2004; Christensen and Christensen 2004; Sen Roy and Balling 2004; Leng et al. 2015). A drought event is defined as a succession of consecutive periods in which the availability of water remains below the threshold level defined by a drought index. According to different states of the hydrological cycle progression, a drought is further categorized into different types such as meteorological, hydrological and agricultural drought (Tallaksen and Van Lanen 2004). Manifestation of meteorological drought starts very quickly, as it only depends on the deficiency of precipitation. Due to the onset condition of the hydrological cycle, however, hydrological drought lags behind meteorological drought. This property of lagging revealed that there is strong linkage between hy-

\footnotetext{
* Corresponding author

E-mail:twkim72@hanyang.ac.kr
}

drological and meteorological droughts (Dracup et al. 1980; Wilhite 2000). Even though the lagging property can be illustrated in the conceptual diagram using lag time, which is defined as the time required by meteorological drought to propagate hydrological drought within the process of the hydrological cycle, presently, there are very limited studies on drought propagation (Vicente-Serrano and LópezMoreno 2005; Van Loon and Laaha 2015; Barker et al. 2016; Shin et al. 2018) and the estimation of lag time due to the complex mechanism of the underlying conditions and climatic variables (Mo 2008; Mishra and Cherkauer 2010; Mishra et al. 2010).

Some researchers investigated the impact of meteorological drought in terms of the time scale to respond to hydrological drought and propagation to hydrological drought. Vicente-Serrano and López-Moreno (2005) and Zhao et al. (2014) have found that the Standardized Runoff Index (SRI) responded well to the four-month time scale of the Standardized Precipitation Index (SPI) and the two-month time scale of the Standardized Evapotranspiration Index (SPEI). 
Similarly, Shin et al. (2018) found the Palmer Hydrological Drought Index (PHDI) responded better to the 3- and 6-month time scale of SPI. In terms of the propagation of drought events, Zhao et al. (2014) found nine out of 11 meteorological drought events were propagated to streamflow droughts. Zhao et al. (2016) estimated that an average of $75.4 \%$ of drought events were propagated to streamflow droughts. There were 33 and $48 \%$ of meteorological drought events that propagated to hydrological drought under the 3- and 6-month time scale of SPI, respectively (Shin et al. 2018).

A few studies focused on the estimation of lag time. $\mathrm{Wu}$ et al. (2016) and Huang et al. (2017) found seasonal variation in lag time from SPI to the Standardized Streamflow Index (SSI). Specifically, a lag time of 127 days was found in comparison between SPI and SRI in the Jinghe River basin of China (Zhao et al. 2014). A seven-month lag time was also found in the Awash River basin of Ethiopia between SPI and SRI (Edossa et al. 2010). At a small drought-prone basin in Oklahoma of the USA, two-month lag time was found between SPI and SRI (Liu et al. 2012).

The majority of these works have focused on the estimation of suitable time scales of meteorological drought to respond to hydrological drought, and few have focused on the estimation of lag time. However, no study has been conducted that explains the relationship of hydrological drought lag time with the characteristics of meteorological drought. This research is novel in the sense that it finds the relationship of lag time on a weekly time scale with the intensity of meteorological drought using probabilistic approaches. The relationship of lag time and meteorological drought intensity is not linear, so it can be explained better by some probabilistic approaches as meteorological drought contains probability information of the successive hydrological drought events (Wong et al. 2013). The main objectives of this study are to identify the best weekly time scale of SPI and SPEI which has a significant relation with SRI, and to figure out the probabilistic relationships of weekly lag time between hydrological drought (SRI) and the meteorological droughts (SPI and SPEI) using a Bayesian network model as well as the spatial distribution of the weekly lag time.

\section{METHODOLOGY}

\subsection{Study Area and Data}

The Han River provides main sources of water for drinking, industry, irrigation, and hydropower generation. The mean annual precipitation in this basin is approximately $1300 \mathrm{~mm}$ with seasonal variations (Chang and Kwon 2007). It has 24 subbasins and here we selected four subbasins for our study as shown in Fig. 1.

The daily precipitation data were obtained from the Korea Meteorological Administration. The daily runoff and evapotranspiration for each subbasin were calculated using the widely adopted TANK model. The daily data were aggregated into the weekly data and then used to estimate the hydrological and meteorological drought in this study.

\subsection{Standardized Precipitation Index (SPI)}

According to the World Meteorological Organization, the SPI is a universal reference drought index to indicate the precipitation conditions in a specific period within a long time series (Hayes et al. 2011). The core advantage of the SPI is the simplicity to calculate drought severity at multiple time scales with only precipitation data. It can be used to monitor short- and long-term water supplies, which can be used for monitoring agricultural and hydrological drought.

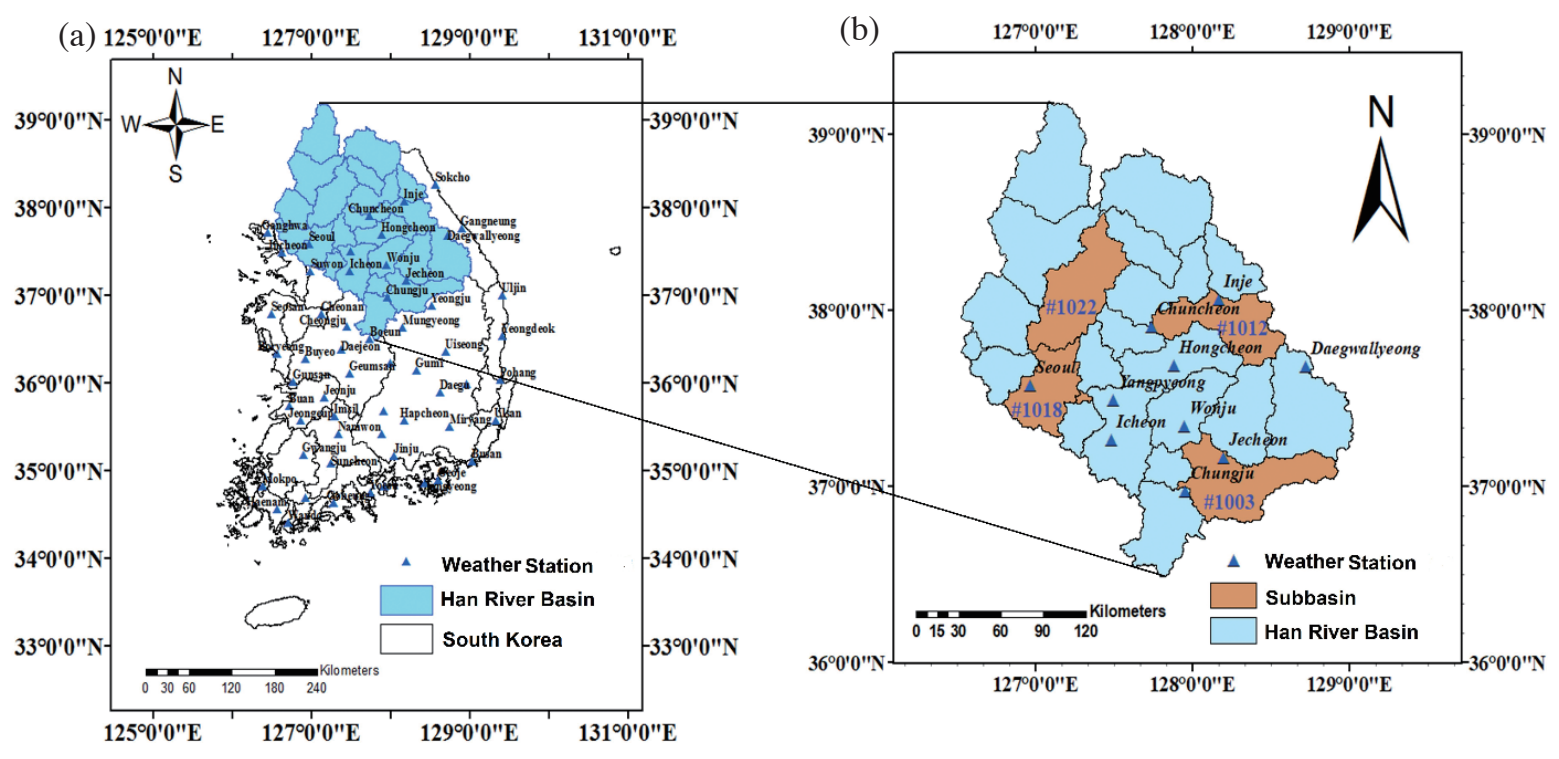

Fig. 1. Location of the Han River basin with subbasins and weather stations. 
To calculate the SPI, first, the precipitation data are fitted to a suitable probability distribution, and then transformed into standard normal distribution having mean zero and standard deviation one. In our study, we considered six available distributions such as gamma, generalized extreme value (GEV), exponential, lognormal, and weibull distribution, employed the Akaike information criterion (AIC) to find the best fitted distribution. After estimating distribution parameters using maximum likelihood method (MLE), according to AIC test as shown in Table 1, two parameters gamma distribution provided the lowest AIC value for the SPI.

\subsection{Standardized Precipitation Evapotranspiration Index (SPEI)}

The SPEI is also used for estimating the meteorological drought. The difference between SPEI and SPI is that the SPEI captures the impact of temperature on water demand through combining temperature into the model to estimate the potential evapotranspiration (PET) (Vicente-Serrano et al. 2010; Kim et al. 2014). A simple water balance equation is used to assess the difference (D) between precipitation (P) and PET, i.e., $\mathrm{D}=\mathrm{P}$ - PET, for a given time scale. The calculation procedure of the SPEI is quite similar to the SPI. After estimating distribution parameters using MLE, according to AIC test as shown in Table 1, GEV distribution provided the lowest AIC value for the SPEI.

\subsection{Standardized Runoff Index (SRI)}

The SRI was used to characterize the hydrological drought in this study. The perception used to calculate the SPI was also employed to calculate the SRI in order to present drought severity at various time scales. Similar to the SPI and SPEI, after estimating distribution parameters using MLE, according to AIC test as shown in Table 1, lognormal distribution provided the lowest AIC value for the SRI.

Table 2 provides four major classifications of drought based on the SPI, SPEI, and SRI.

\subsection{Response Rate}

The response rate was employed in this study to understand the connection between meteorological and hydrological droughts. The response rate was defined as the percentage of meteorological droughts that propagated to hydrological drought through hydrological cycle. If the percentage of propagation is high, this means that hydrological drought is more sensitive to meteorological drought, whereas a lower percentage indicates that the relationship is weak. The mathematical expression of the response rate is given as:

Table 1. AIC values for available distributions for drought indices.

\begin{tabular}{cc|ccc}
\hline & Distribution & \multicolumn{3}{c}{ AIC Value } \\
\hline Name & Probability Density Function & SPI & SPEI & SRI \\
\hline Gamma & $f(x)=\frac{1}{\alpha \Gamma(\beta)}\left(\frac{x}{\alpha}\right)^{\beta-1} \exp \left(-\frac{x}{\alpha}\right)$ & 18700 & 34230 & 27500 \\
GEV & $f(x)=\frac{1}{\alpha}\left[1-\beta\left(\frac{x-x_{0}}{\alpha}\right)\right]^{\frac{1}{\beta}-1} \exp \left\{-\left[1-\beta\left(\frac{x-x_{0}}{\alpha}\right)\right]^{\frac{1}{\beta}}\right\}$ & 20020 & 32320 & 25900 \\
Lognormal & $f(x)=\frac{1}{\sigma_{y} \sqrt{2 \pi}} \frac{1}{x} \exp \left[-\frac{1}{2}\left(\frac{\ln x-\mu_{y}}{\sigma_{x}}\right)^{2}\right], y=\ln x$ & 24350 & 33090 & 25500 \\
Weibull & $f(x)=\frac{\beta}{\alpha}\left(\frac{x}{\alpha}\right)^{\beta-1} \exp \left[-\left(\frac{x}{\alpha}\right)^{\beta}\right]$ & 26290 & 33930 & 26300 \\
Exponential & $f(x)=\lambda \exp (-\lambda x)$ & 20780 & 34590 & 28100 \\
\hline
\end{tabular}

Table 2. Classification of drought severity according to standardized indices.

\begin{tabular}{cc}
\hline SPI/SPEI/SRI & Classification \\
\hline Greater than 0 & No drought \\
-1 to 0 & Mild drought \\
-1.5 to -1 & Moderate drought \\
-2 to -1.5 & Severe drought \\
Less than -2 & Extreme drought \\
\hline
\end{tabular}


$R_{r}=\frac{n}{m} \times 100(\%)$

where $R_{r}$ is the response rate in percentage, $m$ is the number of meteorological droughts during $1967-2013$, while $n$ is the number hydrological droughts responded to meteorological droughts.

\subsection{Bayesian Network Model}

A Bayesian network $(\mathrm{BN})$ is among a family of probabilistic graphical models, incorporating the concept of conditional dependencies on random variables to estimate the relationship between them. It has two parts as shown in Fig. 2: (1) the qualitative part, also called the network structure represented by an arc, and (2) the quantitative part, which incorporates the probability concept associated with each random variable represented by a circle. Based on Bayes' theorem, the relationship among a set of random variables is defined by conditional probabilities, which depend on prior knowledge of random variables. In our study, we have two random variables: a weekly lag time and an intensity of meteorological drought, as shown in Fig. 2. The weekly lag time (' $L T$ ' in Fig. 2) is a dependent variable, whereas the intensity of drought (' $I$ ' in Fig. 2) is an independent variable. Thus, the weekly lag time depends on the intensity of drought. The probability of weekly lag time conditioned on the intensity of meteorological drought is given as:

$\mathrm{P}(L T \mid I)=\frac{\mathrm{P}(I, L T)}{\mathrm{P}(I)}=\frac{\mathrm{C}(I, L T)}{\mathrm{P}(I)}$

where $\mathrm{P}(I)$ and $\mathrm{P}(L T)$ is the probabilities of the intensity of drought and the weekly lag time, respectively. $\mathrm{P}(I, L T)$ is the joint probability between the weekly lag time and the intensity of drought, which can be estimated using a copula function as $\mathrm{C}(I, L T)$.

\section{RESULTS AND DISCUSSION}

\subsection{Identification of Meteorological and Hydrological Droughts}

Meteorological droughts were evaluated on the basis of SPI and SPEI at different weekly time scales in four subbasins of the Han River basin. Most previous studies evaluated the drought events on monthly scales; however, we calculated the SPI and SPEI on 1-, 4-, 8-, 12-, 16-, and 24-week time scale in this study. Being similar to the SPI and SPEI, the SRI was here calculated at 4-week time scale to indicate hydrological drought events in the study area. It is necessary to select a relevant time scale of meteorological drought in order to explain the relationship between meteorological and hydrological droughts. The surface flow (runoff) responded to a short time scale of meteorological drought, while streamflow responded to a long time scale (Zhao et al. 2014). Therefore, Pearson correlation analysis was performed between the different time scales of meteorological drought identified by the SPI and SPEI $(1,4,8$, 12,16 , and 24 weeks) with the hydrological drought identified by the 4-week SRI. As shown in Fig. 3, the correlation coefficient increased significantly from the 1-week to the 8 -week time scale, and with higher time scales more than

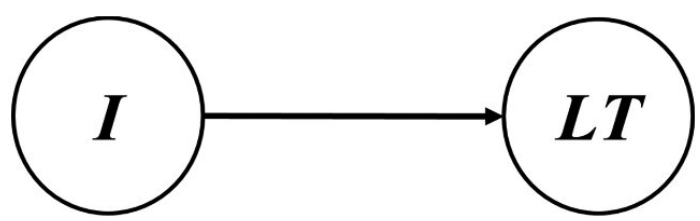

Fig. 2. Schematic representation of a Bayesian Network model.

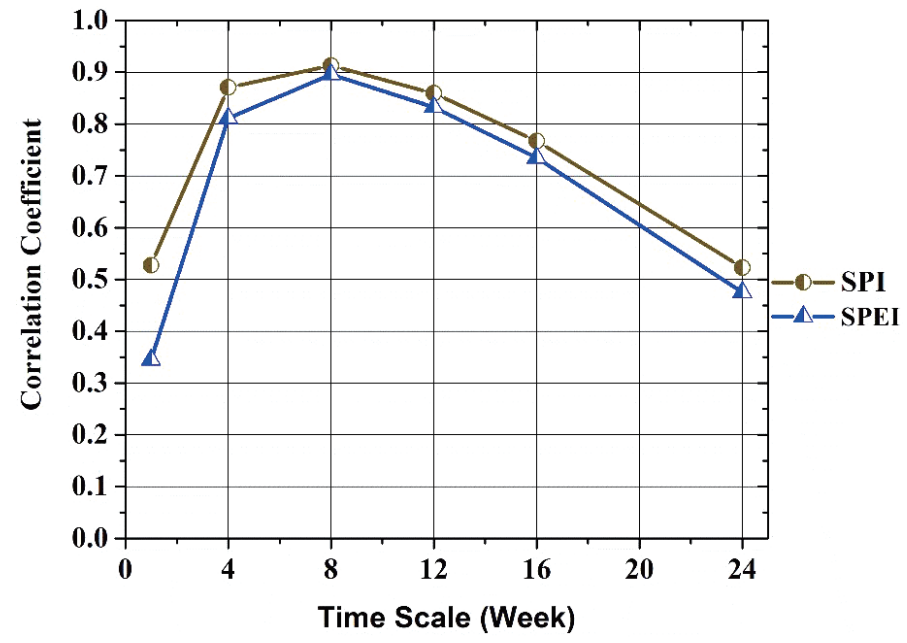

Fig. 3 Correlation coefficients between meteorological and hydrological droughts at different time scales. 
the 8-week, the correlation coefficient decreased gradually. Consequently, in this study, the 8-week time scale of meteorological drought was selected as appropriate to define hydrological drought.

The basic characteristics of meteorological droughts calculated on the 8-week time scale for all subbasins are shown in Table 3. There are many minor droughts identified in both SPI and SPEI time series, so we applied a smoothing approach to pool out these minor droughts (Zhao et al. 2014). The number of drought events identified by the SPEI was higher than those by the SPI, however, the average duration and intensity of the SPEI were less than those of the SPI, except in subbasin \#1003, where the average intensity was more in the case of the SPEI. The reason that a higher number of droughts appeared in the case of SPEI is the involvement of the temperature factor affecting on the change of hydrological balance through evapotranspiration. The distributions of the average intensity in all subbasins estimated by the SPI and SPEI are shown in Fig. 4. Similarly, the characteristics of hydrological drought on the basis of the 4-week SRI are given in Table 3.

\subsection{Relationship Between Meteorological and Hydrological Drought}

The response of hydrological drought to meteorological drought can be explained by the propagation of drought. We used the response rate to describe the percentage of meteorological drought propagated to hydrological drought. Figure 5 shows response rates in percentage for both SPI and SPEI. For SPI, in subbasin \#1003, 86.53\% of meteorological drought events were propagated to hydrological drought, which is very a significant value. In the case of subabsins \#1012, \#1018, and \#1022, the probability of propagation was also very high, and response rates were $82.14,86.79$, and $92.15 \%$, respectively. In the case of SPEI, the probability of meteorological drought propagation was also very high. The estimated maximum response rate was $82.45 \%$ in subbasin \#1022, and in subbasins \#1003, \#1012, and \#1018, the response rates were 67.16, 73.01, and 75.40, respectively.

The propagation of meteorological drought to hydrological drought represented by both SPI and SPEI during $1981-1983$ and 1988 - 1989 are illustrated in Fig. 6. We can see that the hydrological drought responded well to precedent meteorological drought in both cases. In case of SPI, two meteorological droughts pooled to one hydrological drought, while in case of SPEI three drought events pooled to one hydrological drought during 1981 - 1983. Similarly, it can be found that hydrological drought during 1988 1989 has also coupled quite well, pooling of meteorological drought was also observed in this case. These results clarified that the hydrological drought is highly dependent on the meteorological conditions of the basin, and drought events became fewer when propagated from 8-week SPI and SPEI to SRI. These drought properties have been also shown in various studies (Van Loon and Van Lanen 2012; Wong et al. 2013; Barker et al. 2016).

\subsection{Weekly Lag Time and Its Spatial Distribution}

As an indicator of drought propagation, in this study, the lag time was defined as the time taken by meteorological drought to propagate to hydrological drought through the terrestrial part of the hydrological cycle. In this section, the lag time between hydrological and meteorological droughts was estimated using the drought indices, e.g., SPI and SPEI for meteorological drought, and SRI for hydrological drought.

Table 3. Basic characteristics of drought in the study area.

\begin{tabular}{c|c|cccc}
\hline \multirow{3}{*}{ Drought Index } & \multirow{4}{*}{ Characteristics } & \multicolumn{4}{|c}{ Subbasin \# } \\
\cline { 3 - 6 } & & $\mathbf{1 0 0 3}$ & $\mathbf{1 0 1 2}$ & $\mathbf{1 0 1 8}$ & $\mathbf{1 0 2 2}$ \\
\hline \multirow{5}{*}{ 8-week SPI } & No. of drought events & 52 & 56 & 53 & 51 \\
& Mean duration (week) & 25.15 & 23.23 & 26.15 & 27.29 \\
& Mean magnitude & -18.76 & -17.24 & -18.61 & -19.10 \\
& Mean intensity & -0.700 & -0.673 & -0.651 & -0.656 \\
\hline \multirow{5}{*}{ 8-week SPEI } & No. of drought events & 67 & 63 & 61 & 57 \\
& Mean duration (week) & 20.58 & 23.21 & 23.61 & 25.86 \\
& Mean magnitude & -21.92 & -14.44 & -15.12 & -16.03 \\
& Mean intensity & -1.266 & -0.609 & -0.572 & -0.572 \\
\hline \multirow{5}{*}{ 4-week SRI } & No. of drought events & 46 & 46 & 46 & 48 \\
& Mean duration (week) & 27.56 & 28.85 & 28.43 & 27.37 \\
& Mean magnitude & -17.08 & -17.33 & -17.49 & -16.61 \\
& Mean intensity & -0.582 & -0.684 & -0.580 & -0.553 \\
\hline
\end{tabular}



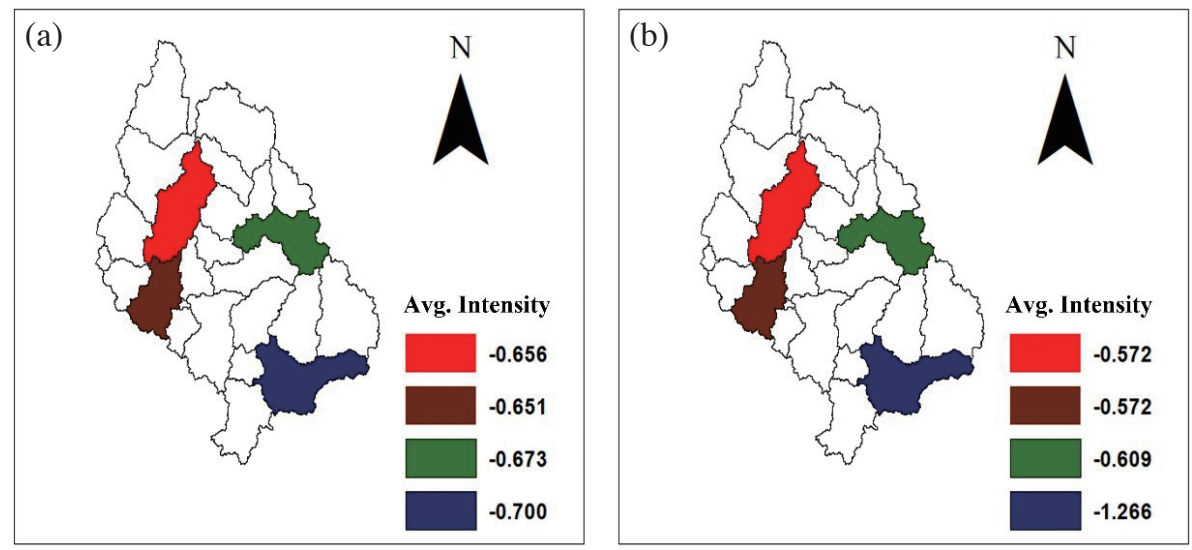

Fig. 4 Average intensity of four subbasins. (a) SPI; (b) SPEI.
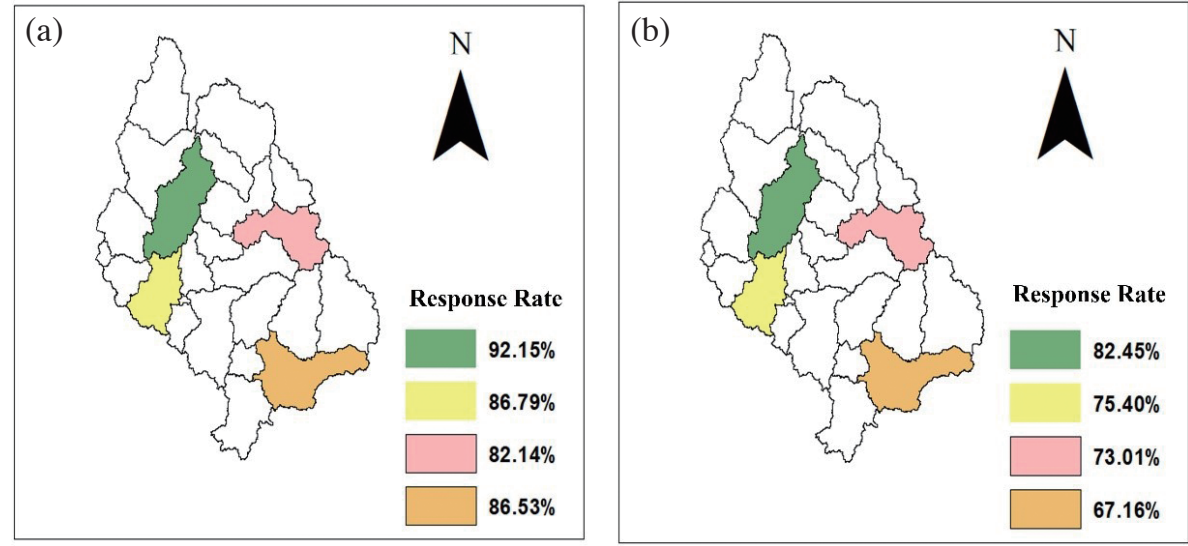

Fig. 5 Response rate (\%) of four subbasins. (a) SPI; (b) SPEI.
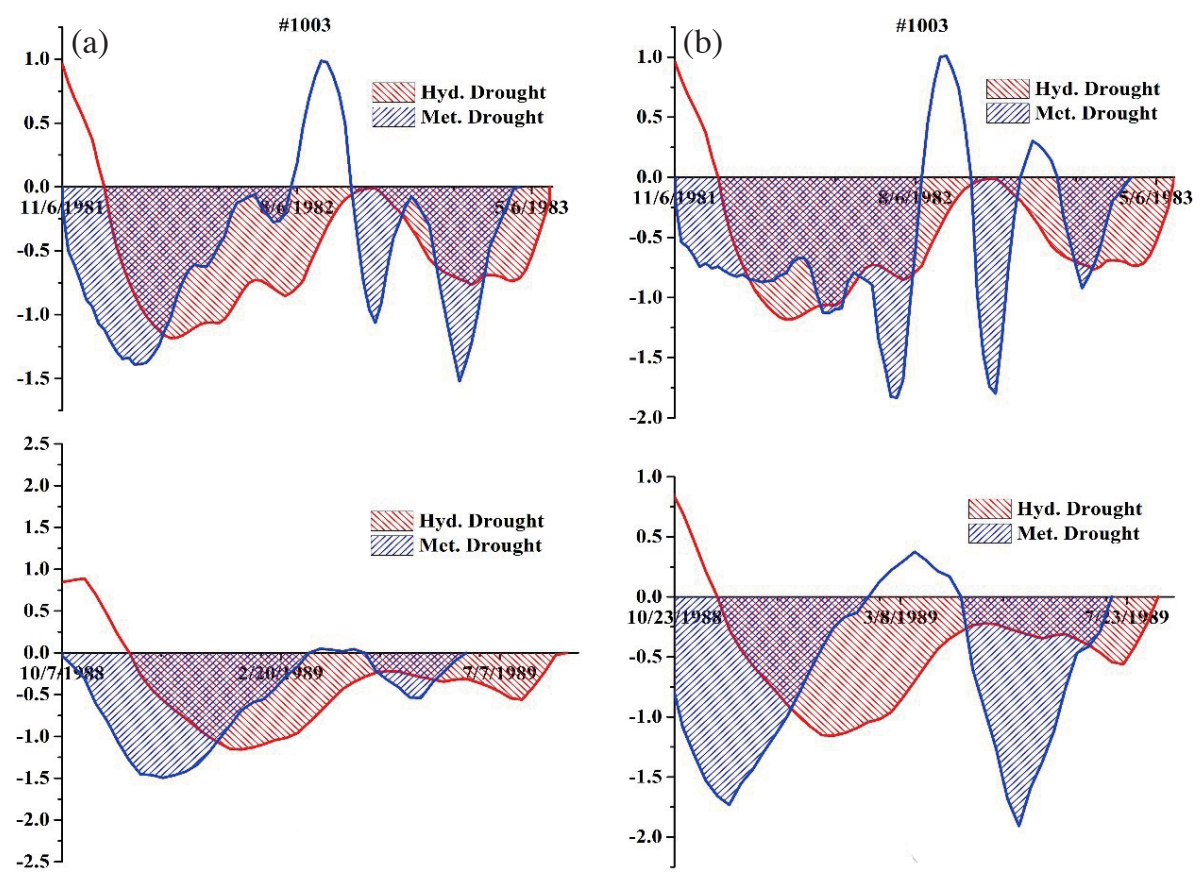

Fig. 6 Example of drought propagation events at subbasin \#1003 during 1981 - 1983 and 1988 -1989. (a) SPI vs SRI; (b) SPEI vs SRI. 
Figure 7 shows the clear concept of the lag time. According to the lag time definition, a meteorological drought may be propagated to hydrological drought whereas a hydrological drought must follow the previous one or more meteorological droughts. We identified meteorological droughts through the SPI and SPEI and marked the time when they started. If a hydrological drought was identified through the SRI followed the corresponding previous meteorological drought, then its starting time was also marked. The time difference was counted to estimate mathematically lag times. According to Zhao et al. (2014), the onset time of hydrological drought lags behind meteorological drought by a short duration and when the time duration increases, for example, in the case of 12-month SPI, the time of the onset of hydrological drought tends to be earlier than the meteorological drought in most of the drought events. Thus, the long time scales of SPI and SPEI were unsuitable for early warning of hydrological drought since it happened after the start of hydrological drought or at the same time.

The temporal variations of the weekly lag time are shown in Fig. 8, in which the weekly lag times with respect to all drought events estimated from 1973 - 2013 using SPI and SPEI are illustrated. At subbasin \#1003, the weekly lag time varied between 5 and 12 weeks in the case of SPI, while it varied from 4 and 11 weeks in SPEI. In subbasin
\#1012, the weekly lag time was from 4 to 11 weeks in both cases of SPI and SPEI. In subbasin \#1018, it was observed that the minimum weekly lag time was 5 weeks and the maximum was 11 weeks in the case of SPI, while the minimum weekly lag time was 5 weeks and the maximum was 10 weeks in the case of SPEI. Lastly, in subbasin \#1022, the maximum weekly time lag was observed as 14 weeks and the minimum was 5 weeks in the case of SPI, while the maximum and the minimum were observed as 12 and 5

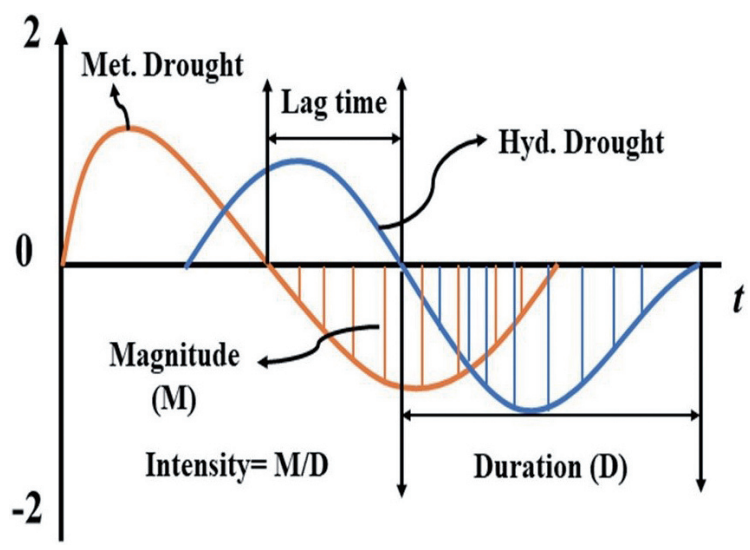

Fig. 7. Definition of drought characteristics.
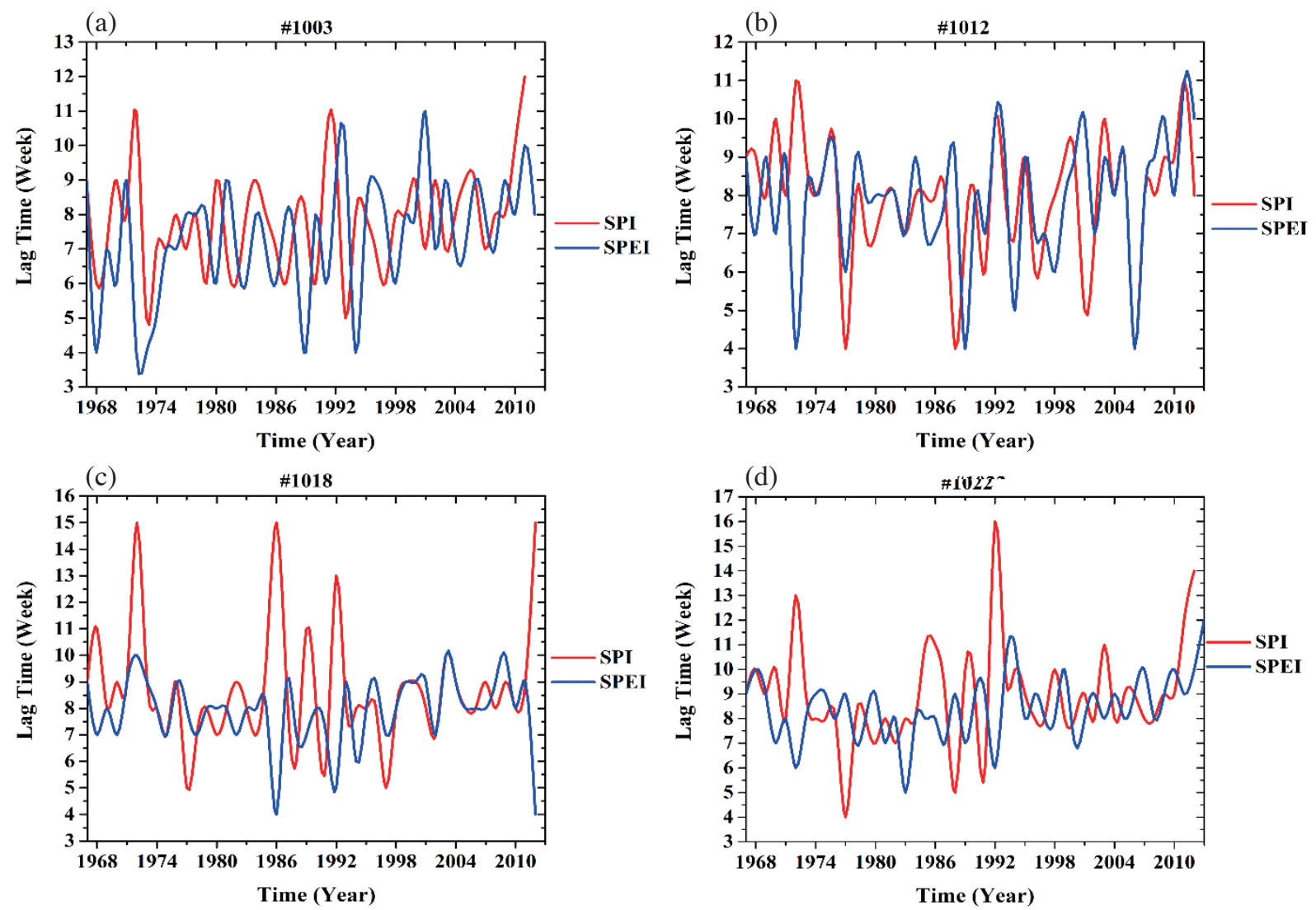

Fig. 8. Temporal variation of lag time with the progression of drought events (a) \#1003 (b) \#1012 (c) \#1018 (d) \#1022. 
weeks, respectively, in the case of SPEI. The reason for spatial distribution in the weekly lag time is the variation in annual average precipitation and seasonal distribution of runoff from each subbasin. The annual average precipitation of some subbasins located in the western and central regions, such as \#1018 and \#1022 have high annual average precipitation of 1291 and $1292 \mathrm{~mm}$, respectively, as compared to subbasin \#1012 and \#1003, which are located on the eastern and south-eastern side of the Han River basin (Yoon et al. 2013). Other important factors for this spatial variation is the seasonal distribution of runoff generated from each subbasin. In subasin \#1003 and \#1012, the runoff generated is high in spring season, while in the case of subbasin \#1018 and \# 1022, the runoff generated have high percentage in the summer season.

The variations of weekly lag time are illustrated with the intensity of meteorological drought in Fig. 9. These results showed that the longer weekly lag time was observed when the intensity of meteorological drought was low, and vice versa. In addition, the intensity of drought events represented by the SPEI was less as compared with the SPI. The reason behind this is that the SPEI incorporates precipitation and evapotranspiration, while the SPI only considers the precipitation factor. It is clearly observed from Fig. 9 that even though the weekly lag times were same for both the
SPI and SPEI, the intensity of drought was quite different. In other words, the SPEI calculated a lower intensity drought, while the SPI has higher intensity droughts. The other possible reasons for the weekly lag time variation is the seasonality factor, water demands for drinking and irrigation, and climate change. Additionally, the intensity of meteorological drought for all drought events was in the range of mild drought as shown in Fig. 9, because it became weak through averaging the SPI and SPEI values in the pooling procedure. However, in the case of raw meteorological droughts as shown in Fig. 6, many drought events were classified as 'moderate drought', 'severe drought' or 'extreme drought'.

\subsection{Probabilistic Relationship}

A Bayesian network model was used here to model the probability between random variables. We have two random variables: the weekly lag time and the intensity of metrological drought. Thus, we used Eq. (2) to calculate the probability of the weekly lag time conditioned on the intensity of meteorological drought for both indices. Since we have event-based data from 1967 - 2013, so we applied a Poisson distribution to find the marginal probability of the weekly lag time and the intensity of drought. To calculate the joint probability of the weekly lag time and the intensity of drought,
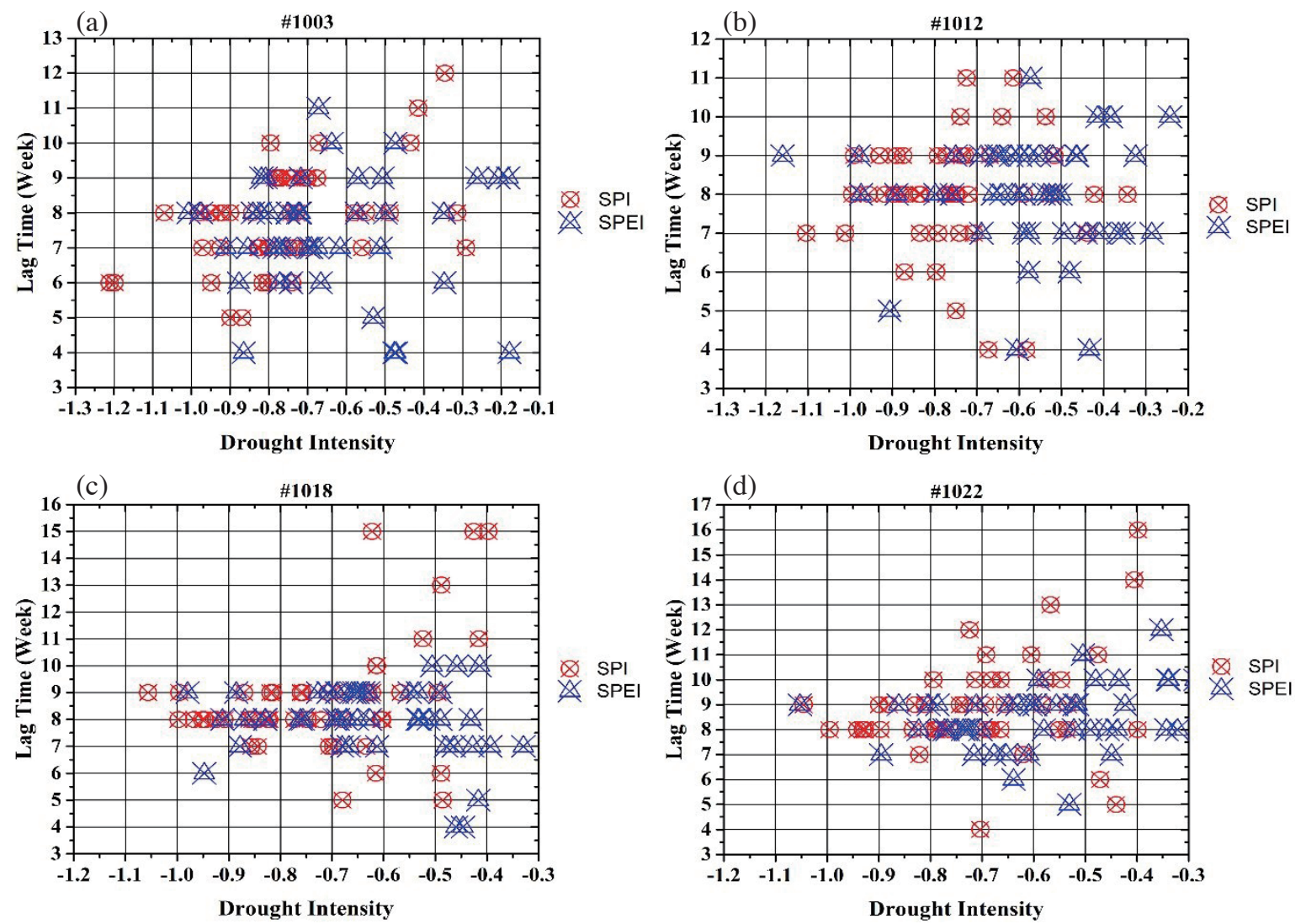

Fig. 9. Relations between the lag time and the intensity of SPI and SPEI (a) \#1003 (b) \#1012 (c) \#1018 (d) \#1022. 
four types of copula functions, Gaussian, T, Gumbel, and Clayton were investigated. Based on the p-value of Kolmogorov-Smirov test, Gaussian copula was chosen as the best among other, as shown in Table 4.

For a clear understanding of the probabilistic relationship, we took four values of intensities ranging between -1.0 to $-0.9,-0.9$ to $-0.8,-0.8$ to -0.7 , and -0.7 to -0.6 and assigned them as $\mathrm{I}_{1}, \mathrm{I}_{2}, \mathrm{I}_{3}$, and $\mathrm{I}_{4}$, respectively. Figures 10 and 11 showed the probabilistic curves of intensities calculated from the SPI and SPEI conditioned on the weekly lag time, respectively. These figures clearly indicate that the probability of occurrence of the same weekly lag time increases as the intensity decreases. For example, in subbasin \#1003, if the intensity of meteorological drought is $I_{1}$, as shown in Fig. 10a, the probability that a weekly lag time becomes 10 weeks is about $87 \%$, and this probability increases from $97-100 \%$ when the intensity decreases from $\mathrm{I}_{2}$ to $\mathrm{I}_{4}$, respectively. In subbasin \#1012, if the intensity is $\mathrm{I}_{1}$, then the probability that a weekly lag time becomes 10 weeks is $67 \%$, and increases to 80,91 , and $98 \%$ at intensities of $\mathrm{I}_{2}, \mathrm{I}_{3}, \mathrm{I}_{4}$, respectively. In subbasins \#1018 and \#1022, the weekly lag time variation is higher as compared to subbasins \#1003 and \#1012. In this case, the probability that a weekly lag time becomes 10 weeks is $100 \%$ from all intensities, but the trend is the same for that a weekly lag time
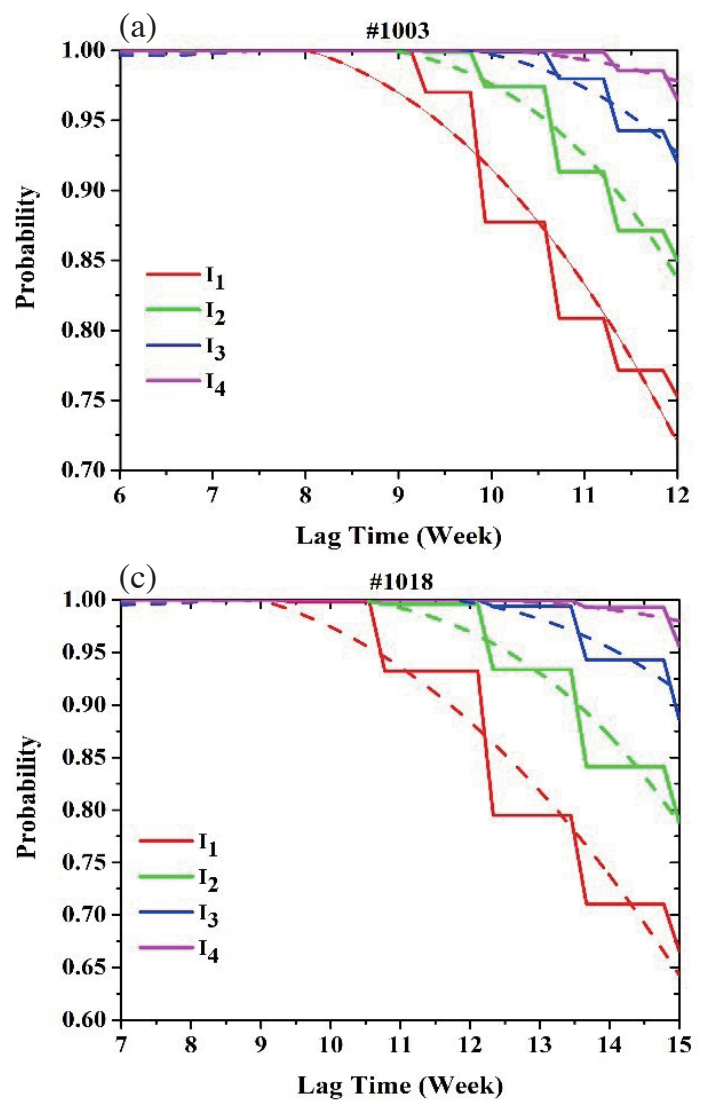

becomes more than 10 weeks. The probability of certain weekly lag time increases with the decrease of the intensity. In the case of SPEI, as shown in Fig. 11, the probabilities curve showed the similar trend as in the case of SPI. The probability of occurring of weekly lag time increases with the decrease of the intensity.

Similar to the SPI, the spatial variation of weekly lag time was also observed as shown in Fig. 11. If we compare Figs. 10 and 11, the probability of a weekly lag time at the same intensity is different in both cases of SPI and SPEI. For example, in subbasin \#1003, as shown in Figs. 10a and 11a, if the intensity of meteorological drought is $I_{1}$, then the probability of occurrence of 10 -week lag time is $87 \%$ in the case of SPI and $60 \%$ in the case of SPEI. The same scenario was observed in all other subbasins. The

Table 4. Statistics of K-S GOF test to find best copula joining the marginal.

\begin{tabular}{cc}
\hline Copula & P-Value \\
\hline Gaussian & 0.991 \\
$\mathrm{~T}$ & 0.985 \\
Gumbel & 0.789 \\
Clayton & 0.812 \\
\hline
\end{tabular}
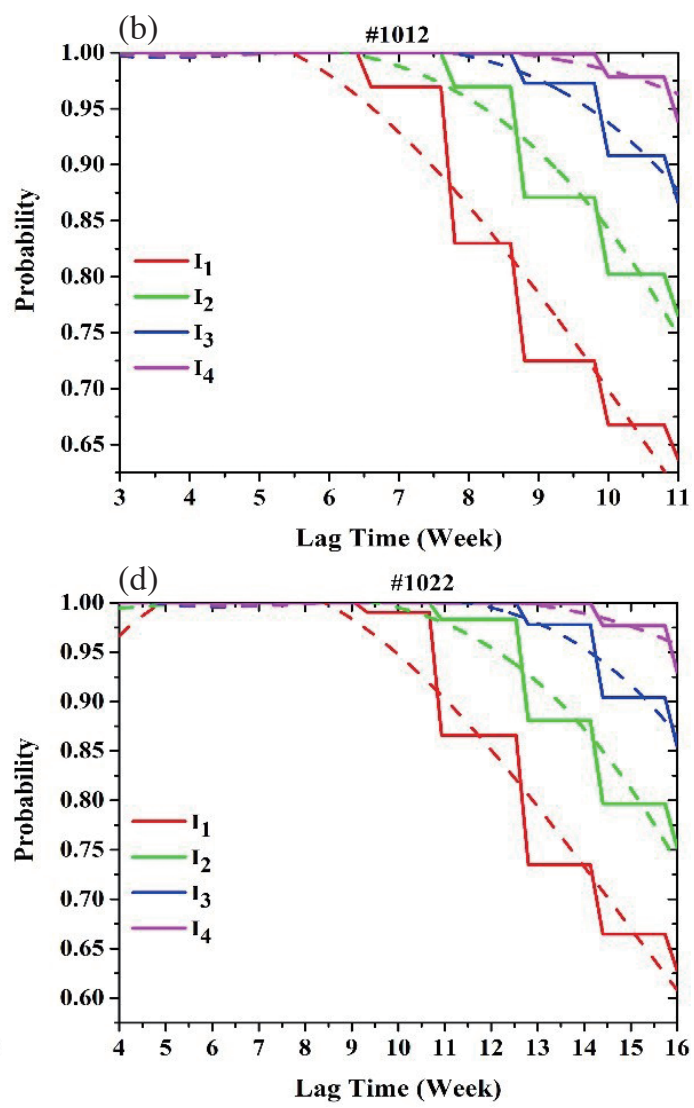

Fig. 10. Probability of lag time occurrence conditioned on the intensity of meteorological drought (SPI) (a) \#1003 (b) \#1012 (c) \#1018 (d) \#1022. 

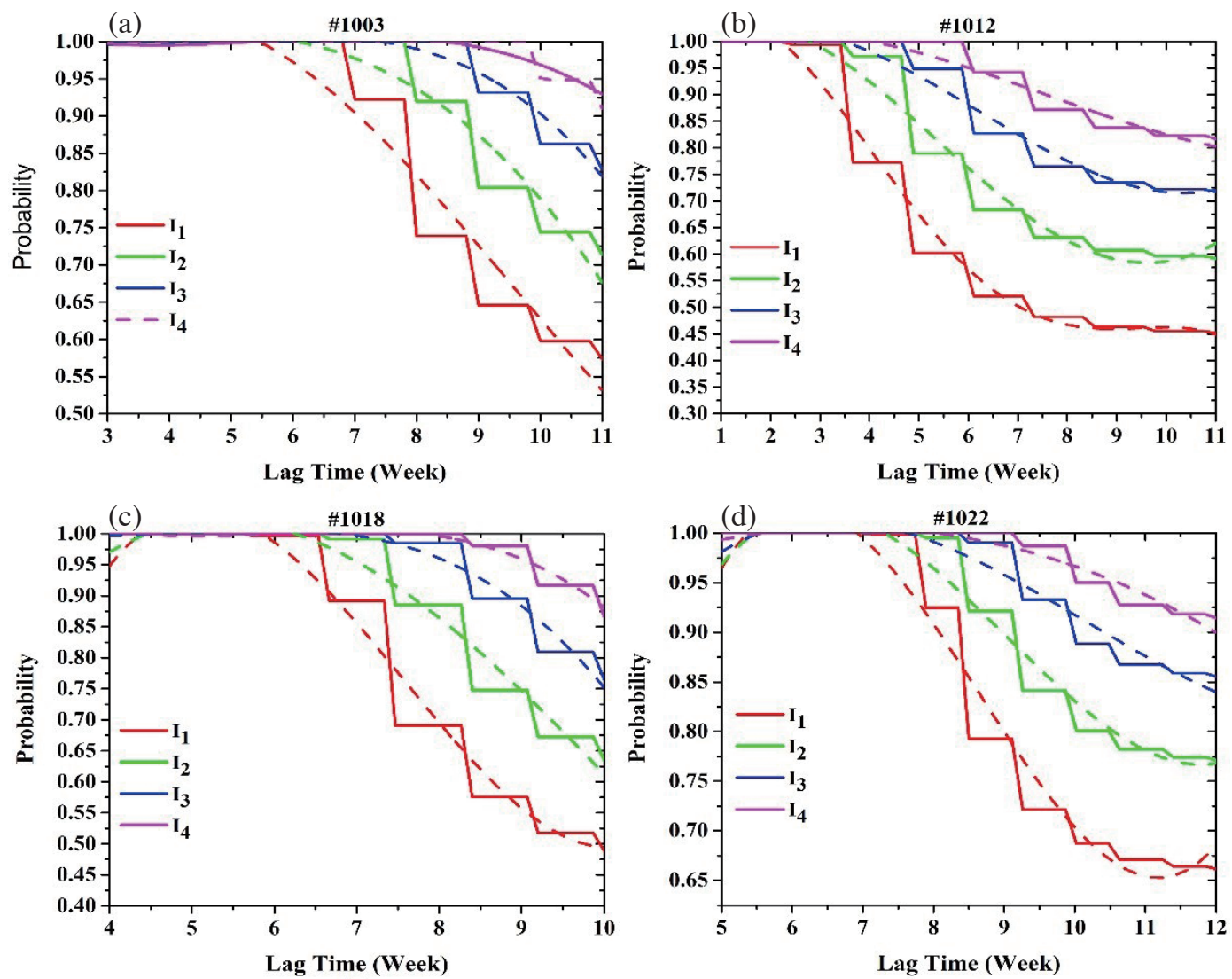

Fig. 11. Probability of lag time occurrence conditioned on intensity of meteorological drought (SPEI) (a) \#1003 (b) \#1012 (c) \#1018 (d) \#1022.

above results are clearly well in accordance with Fig. 9 and indicated that the probability of occurrence of weekly lag time increases with decrease of the intensity, and there is spatial variability of probability of the same lag time in all other subbasins.

\section{CONCLUSION}

It is very important to know the lag time and its relationship with the characteristics of meteorological drought for the early warning and mitigation process of hydrological drought. Therefore, this study developed a probabilistic relationship of weekly lag time with the intensity of precedent meteorological drought using propagation and a Bayesian network model. We estimated the meteorological droughts from two different indices, i.e., SPI and SPEI on a weekly time scale, and found the best time scale using the correlation analysis with a hydrological drought index. To show the propagation of meteorological drought to hydrological drought, we used the response rate, which showed a significant percentage in all subbasins as well as for both indices. The quantitative analysis revealed that the weekly lag time varied under different intensities of meteorological drought and varied spatially as well. In the case of SPEI, the overall intensity of drought was less as compared with the SPI, however, the occurrence of weekly lag time was not much different. Finally, the probability of the occurrence of a weekly lag time conditioned on the intensity of meteorological drought was calculated for different intensities using a Bayesian network model. In both cases, it was found that the probability of occurrence of a weekly lag time increased if the intensity decreased. However, it varied spatially as well as with the method used to calculate intensity. Even though the results of this study are quite specific to the study area, the results and the techniques developed in this study would be helpful for making early mitigation plans for hydrological drought and for forecasting.

Acknowledgements This work is supported by the Korea Agency for Infrastructure Technology Advancement (KAIA) grant funded by the Ministry of Land, Infrastructure and Transport (Grant 17AWMP-B083066-04). The authors would like to acknowledge the Higher Education Commission (HEC) of Pakistan and the Government of Pakistan for granting a scholarship to Muhammad Nouman Sattar to pursue his $\mathrm{PhD}$ degree from Hanyang University, Korea.

\section{REFERENCES}

Barker, L. J., J. Hannaford, A. Chiverton, and C. Svensson, 
2016: From meteorological to hydrological drought using standardised indicators. Hydrol.Earth Syst. Sci., 20, 2483-2505, doi: 10.5194/hess-20-2483-2016. [Link]

Beniston, M. and D. B. Stephenson, 2004: Extreme climatic events and their evolution under changing climatic conditions. Global Planet. Change, 44, 1-9, doi: 10.1016/j. gloplacha.2004.06.001. [Link]

Chang, H. and W.-T. Kwon, 2007: Spatial variations of summer precipitation trends in South Korea, 1973-2005. Environ. Res. Lett., 2, 045012, doi: 10.1088/17489326/2/4/045012. [Link]

Christensen, O. B. and J. H. Christensen, 2004: Intensification of extreme European summer precipitation in a warmer climate. Global Planet. Change, 44, 107-117, doi: 10.1016/j.gloplacha.2004.06.013. [Link]

Dracup, J. A., K. S. Lee, and E. G. Paulson, 1980: On the definition of droughts. Water Resour. Res., 16, 297302, doi: 10.1029/wr016i002p00297. [Link]

Edossa, D. C., M. S. Babel, and A. Das Gupta, 2010: Drought analysis in the Awash river basin, Ethiopia. Water Resour. Manag., 24, 1441-1460, doi: 10.1007/ s11269-009-9508-0. [Link]

Hayes, M., M. Svoboda, N. Wall, and M. Widhalm, 2011: The Lincoln declaration on drought indices: Universal meteorological drought index recommended. Bull. Amer. Meteorol. Soc., 92, 485-488, doi: 10.1175/2010bams3103.1. [Link]

Huang, S., P. Li, Q. Huang, G. Leng, B. Hou, and L. Ma, 2017: The propagation from meteorological to hydrological drought and its potential influence factors. J. Hydrol., 547, 184-195, doi: 10.1016/j.jhydrol.2017.01.041. [Link]

Kim, B. S., I. H. Park, and S. R. Ha, 2014: Future projection of droughts over South Korea using Representative Concentration Pathways (RCPs). Terr. Atmos. Ocean. Sci., 25, 673-688, doi: 10.3319/TAO.2014.03.13.01(Hy). [Link]

Kunkel, K. E., 2003: North American trends in extreme precipitation. Nat. Hazards, 29, 291-305, doi: 10.1023/A:1023694115864. [Link]

Leng, G., Q. Tang, and S. Rayburg, 2015: Climate change impacts on meteorological, agricultural and hydrological droughts in China. Global Planet. Change, 126, 2334, doi: 10.1016/j.gloplacha.2015.01.003. [Link]

Liu, L., Y. Hong, C. N. Bednarczyk, B. Yong, M. A. Shafer, R. Riley, and J. E. Hocker, 2012: Hydro-climatological drought analyses and projections using meteorological and hydrological drought indices: A case study in Blue River Basin, Oklahoma. Water Resour. Manag., 26, 2761-2779, doi: 10.1007/s11269-012-0044-y. [Link]

Mishra, V. and K. A. Cherkauer, 2010: Retrospective droughts in the crop growing season: Implications to corn and soybean yield in the Midwestern United States. Agric. For. Meteorol., 150, 1030-1045, doi: 10.1016/j.agrformet.2010.04.002. [Link]
Mishra, V., K. A. Cherkauer, and S. Shukla, 2010: Assessment of drought due to historic climate variability and projected future climate change in the midwestern United States. J. Hydrometeorol., 11, 46-68, doi: 10.1175/2009jhm1156.1. [Link]

Mo, K. C., 2008: Model-based drought indices over the United States. J. Hydrometeorol., 9, 1212-1230, doi: 10.1175/2008jhm1002.1. [Link]

Sen Roy, S. and R. C. Balling, 2004: Trends in extreme daily precipitation indices in India. Int. J. Climatol., 24, 457-466, doi: 10.1002/joc.995. [Link]

Shin, J. Y., S. Chen, J.-H. Lee, and T.-W. Kim, 2018: Investigation of drought propagation in South Korea using drought index and conditional probability. Terr. Atmos. Ocean. Sci., 29, 231-241, doi: 10.3319/ TAO.2017.08.23.01. [Link]

Tallaksen, L. M. and H. A. J. Van Lanen, 2004: Hydrological Drought: Processes and Estimation Methods for Streamflow and Groundwater, Elsevier, 579 pp.

Van Loon, A. F. and G. Laaha, 2015: Hydrological drought severity explained by climate and catchment characteristics. J. Hydrol., 526, 3-14, doi: 10.1016/j.jhydrol.2014.10.059. [Link]

Van Loon, A. F. and H. A. J. Van Lanen, 2012: A processbased typology of hydrological drought. Hydrol. Earth Syst. Sci., 16, 1915-1946, doi: 10.5194/hess-16-19152012. [Link]

Vicente-Serrano, S. M. and J. I. López-Moreno, 2005: Hydrological response to different time scales of climatological drought: An evaluation of the Standardized Precipitation Index in a mountainous Mediterranean basin. Hydrol. Earth Syst. Sci., 9, 523-533, doi: 10.5194/hess-9-523-2005. [Link]

Vicente-Serrano, S. M., S. Beguería, and J. I. López-Moreno, 2010: A multiscalar drought index sensitive to global warming: The standardized precipitation evapotranspiration index. J. Climate, 23, 1696-1718, doi: 10.1175/2009jcli2909.1. [Link]

Wilhite, D. A., 2000: Drought as a natural hazard: Concepts and definitions. Drought: A Global Assessment, Vol. 1, Routledge, London, 3-18.

Wong, G., H. A. J. Van Lanen, and P. J. J. F. Torfs, 2013: Probabilistic analysis of hydrological drought characteristics using meteorological drought. Hydrolog. Sci. J., 58, 253-270, doi: 10.1080/02626667.2012.753147. [Link]

Wu, J., X. Chen, L. Gao, H. Yao, Y. Chen, and M. Liu, 2016: Response of Hydrological Drought to Meteorological Drought under the Influence of Large Reservoir. $A d v$. Meteorol., 2016, 1-11, doi: 10.1155/2016/2197142. [Link]

Yoon, S.-K., J.-S. Kim, J.-H. Lee, and Y.-I. Moon, 2013: Hydrometeorological variability in the Korean Han River Basin and its sub-watersheds during different 
El Niño phases. Stoch. Environ. Res. Risk Assess., 27, 1465-1477, doi: 10.1007/s00477-012-0683-9. [Link]

Zhao, L., A. Lyu, J. Wu, M. Hayes, Z. Tang, B. He, J. Liu, and M. Liu, 2014: Impact of meteorological drought on streamflow drought in Jinghe River Basin of China. Chin. Geogr. Sci., 24, 694-705, doi: 10.1007/s11769- 014-0726-x. [Link]

Zhao, L., J. Wu, and J. Fang, 2016: Robust response of streamflow drought to different timescales of meteorological drought in Xiangjiang River Basin of China. Adv. Meteorol., 2016, 1-8, doi: 10.1155/2016/1634787. [Link] 